comparatively small area of fertile land is of great importance. Since the rainfall is almost negligible, the irrigation of the country depends on the Nile. The Delta provides part of Egypt with a complete system of natural canals, and so it is possible to irrigate this part of Egypt at any time of the year and thus two or three crops can be grown annually. Along the banks of the Nile are situated a number of fertile areas called 'isolated basins' separated from one another by desert patches extending to the river's edge. The Nile is low for three months every year. It begins its rise of approximately 20 feet in May and from August to October all the isolated basins are flooded. When it subsides, one crop can be raised. Further irrigation is provided by primitive native water elevators, the water being elevated from wells and discharged into channels leading to the fields. The Egyptian Government has decided on an electrification scheme which will enable the land to be irrigated and drained in an adequate way. The contract for the supply and erection of the necessary overhead transmission lines, some of which are carried by towers across the Nile, others in underwater cables, has been given to the General Electric Co. by the Egyptian Government. In the G.E.C. Journal of August, a full description is given of the scheme by C. S. Ickringill and H. Peters. Power is generated at 3,300 volts, stepped up to 33,000 volts and transmitted to the pumping stations. A photograph is shown of the two lattice towers supporting the power cables across the Nile at Idfu.

\section{Increasing the Speed of Atlantic Liners}

Frve years ago, four of the turbine vessels of the Hamburg-Amerika line were equipped with new turbines and water-tube boilers, so as to increase their output from 15,000 to 28,000 horse-power. This effected an increase in the speed of the vessels from 16 to $19 \cdot 2 \mathrm{knots}$ and reduced the time taken from Cherbourg to New York from 8 to $6 \frac{1}{2}$ days. The results of experiments and tug tests carried out with a model of the ships by the Hamburg Shipbuilding Testing Federation showed that considerable economies could be effected in the fuel consumption by altering the shape of the vessels. It was decided to increase their length by about forty feet and reinforce the hull structure so as to make it similar to the Europa. It is computed that the saving thus effected will in three years' time compensate for the total cost of the reconstruction, which was carried out by Messrs. Blohm and Voss of Hamburg. During last winter, the vessels were withdrawn from service one after the other and new bows were fitted. As these bows had been previously constructed, the time that each vessel remained in the dockyard did not exceed 60 days. The old bow was burned away from the hull by oxy-acetylene blowpipes and the new bow was drawn towards the hull and kept in position by grappling irons. All the shell plates were electrically welded together and also nearly all the other connexions, including the floor plates, pillars and girders. Interesting illustrations of electric-welded ship construction by Messrs. Blohm and Voss are shown in Electric Welding of August.

\section{'Dry Ice' in the Machine Shop}

By means of solid carbon dioxide, often called 'dry ice', it is easy to lower the temperature of a piece of metal to 100 degrees below zero Fahrenheit. At this temperature, the metal contracts considerably and so the workman can obtain a good 'shrink fit'. It is analogous to the riveting of boiler plates by red hot rivets, which on cooling draw the plates so tightly together as to form a joint impervious to high pressure steam. According to Science Service of Washington, W. H. Swanger of the U.S. Bureau of Standards, who has been conducting experiments with solid carbon dioxide, reports that machine shop practice may come to accept this new method of shrinking metals. When a metal band has to be slipped round a shaft it is necessary to heat it, and as it cools it contracts to a tight fit. Instead of doing this we can refrigerate the shaft causing it to contract, and thus enabling the band to be slipped in place. When the shaft warms to room temperature a tight fit is secured. As the domestic production of frozen carbon dioxide has in recent years exceeded 40,000 tons it is commercially available. Mr. Swanger concludes that the shrinking of metals with very low temperatures is commercially feasible.

\section{Speculative Borings in the Earth's Crust}

THE heat generated in the interior of the earth's crust has puzzled men of science for centuries. In recent years, radical changes have been made in the theory of what causes this heat. A modern theory is that there is no heat from radioactive materials at greater depths than 12 miles. Heat is also due to the oxidation of iron and friction of slipping rocks. The present high price of gold has turned the attention of South African engineers to the possibility of boring their mines deeper. In the Heaton Works Journal of June an interesting account is given of the work done by Sir Charles Parsons in this connexion, and on the proposals he made for sinking a bore hole 12 miles deep. He proposed an arrangement of brinecooling by large steel pipes connected at the top and bottom of each half mile section by a closed ring. There would be air-locks also every two or three miles so as to prevent the air pressure from becoming excessive. The real difficulty in the way of boring a hole to a great depth lies in the cost of the undertaking, and in the fact that a financial return cannot be guaranteed. Practically the only inducement to business men to explore the depths of the earth by sinking a deep hole is the chance of finding rich deposits of precious metals. If this is ever done it would put the speculations of men of science to the acid test of practice.

\section{Rabbits and Steel Traps}

ONCE again the R.S.P.C.A. rabbit week in Great Britain (October 6-13) is being made the occasion of an effort to obtain support for the Bill promoted by the University of London Animal Welfare Society to prohibit the import, manufacture, sale, exposure for sale, possession, custody or use of steel traps or gins. This Bill has now reached the final stages of drafting, and 
will be introduced early in the new session. Viscount Tredegar will introduce it in the House of Lords, while Mr. Linton Thorp has consented to take charge of it when it reaches the House of Commons. Apart from the humanitarian aspect of the steel trap problem, there is another which assumes national importance, inasmuch as it has a vital bearing on agriculture. To agriculturists, the rabbit is a pest, and its extermination would be of great benefit to farmers. Paradoxical as it may seem, the steel trap is beginning to be suspect as an exterminator-and this in districts which have hitherto been wedded to its use. In certain portions of Carmarthenshire and in Pembrokeshire, traps were not used before the War, and rabbits were kept down by other means; since the introduction of the steel trap, these districts are overrun with rabbits.

\section{New Uses for Bone Glue}

THE results of the competition organised by the International Association of Bone Glue Manufacturers ("Epidos"), with the object of extending the uses of bone glue, have recently been announced, and the sum of 30,000 Swiss franes has been distributed among thirty competitors representing ten Continental countries; the fact that this is 10,000 francs in excess of the amount to be distributed under the rules of the competition may be taken as an indication of the high standard of the contributions. It is remarkable that few of the winning memoranda refer to what is usually regarded as the obvious and most common use for glue, namely, as an adhesive. They are, indeed, characterised by the diversity of their interests, and include processes in which glue is used as a stabiliser for colloids (for example, in latex preparations, polishes and ceramic products); as a source of nitrogen in the production of yeast; to enhance resistance (for example, of rubber) to oils and spirits; and as a catalyst, for example, to inhibit the action of acid pickle-liquor. There also appears to be a wide range of uses for glue as an ingredient of plastics, moulding and insulating materials and lacquers, and as a dressing for textiles. Full particulars of each process are obtainable from the General Secretariat of Epidos, 40, Rue du Colisée, Paris. International competitions of this kind suggest a novel method of obtaining technical information which doubtless will prove popular with prospective inventors. In the present instance, the experiment certainly appears to have justified itself, since it is announced that a further competition will be organised in the near future.

\section{B.D.H. Products}

The British Drug Houses Ltd., London, N.l, have issued a handy brochure entitled "B.D.H. Injections for Parenteral Medication". It contains a list of drugs which are commonly given by injection, a brief note of their use and the range of dosage recommended, together with the packings obtainable and their cost. It is stated that the preparation of the solutions is carried out in a specially designed room, provided with double doors and supplied with filtered air at a pressure slightly in excess of atmospheric. The ampoules and bottles used are made of standard alkali-free amber glass and are sterilised after filling by an approved method, the actual process adopted being one which exerts no deleterious action on the medicament. Where containers designed to permit the withdrawal of successive doses on different occasions are employed, a small quantity of antiseptic is added to the solution. "Glucotest Solution" B.D.H. provides a simple and rapid method for determining the amount of sugar in urine. 2 c.c. of the solution is boiled in a test tube with a small amount of Glucotest powder to prevent bumping and the urine is added drop by drop from a pipette. The addition of urine is continued until the blue colour of the liquid has completely disappeared and a white or yellow colour free from any suggestion of green remains. The amount of glucose in the urine is inversely proportional to the number of drops required, and is ascertained directly from a table supplied with the solution.

\section{Cosmic Radiation}

No. 4 of the Annals of the Observatory of Lund, 1934, is devoted to a memoir in English, entitled "Cosmic Ultra-Radiation in Northern Sweden (an Academical Dissertation)" by Axel Corlin. It is an admirably printed quarto volume containing 113 pages of text and 80 pages of tables and bibliography. The author made measurements of the cosmic radiation in the far north of Sweden, using a Kolhörster apparatus in 1929-30 and a Steinke apparatus in 1932-34. A careful study is made of the relation between the radiation measured, and the air pressure, air temperature and humidity, using the method of multiple correlation. No direct influence of air temperature and humidity was found. Likewise no positive relation was established, after exhaustive investigation, between the cosmic radiation and magnetic storms and auroræ. The transition effect in iron was observed in a lake near Abisko, with results similar to those found by Steinke at Königsberg. The ionisation by cosmic radiation was measured in the Kirunavaara iron mine, and was detected down to 700 metres water-equivalent. The volume contains two chapters of great general interest, one giving a historical summary of the experimental and theoretical development of cosmic ray investigation, while the other discusses the origin of the radiation, the present situation of this problem being described as "quite desperate".

\section{Measurement of Geological Time}

IN 1931, H. V. Ellsworth analysed a specimen of uraninite from Manitoba and obtained a lead-ratio with the surprisingly high value of $0 \cdot 260$, corresponding to an age of about 1,750 million years. Although Ellsworth gave adequate evidence that the mineral was of first class quality, there has naturally been some hesitation in accepting this great extension of geological time. Confirmation of the most convincing kind is now, however, forthcoming. It is announced by Prof. A. C. Lane through Science Service, Washington, D.C., that Miss Edith Kroupa (working in the laboratory of Dr. F. Hecht in Vienna) has 